\title{
The Effects of Matrine in Combination with Docetaxel on Castration-Resistant (Androgen-Independent) Prostate Cancer
}

This article was published in the following Dove Press journal: Cancer Management and Research

Qi Li'
Jia Xu'
Zheng He
Xue Wen'
Fengmei Wang'
Peng Zhang'
Jun Li'
Bei Song'
Qingyong Wang '
Ronghai Li'
Hai Huang
'Department of Clinical Laboratory of
Xiyuan Hospital, China Academy of
Chinese Medical Sciences, Beijing,
I0009I, People's Republic of China;
${ }^{2}$ Department of Clinical Laboratory, The
PLA General Hospital, Beijing I00853,
People's Republic of China; ${ }^{3}$ Department
of Urology, The Sun Yat-Sen Memorial
Hospital, Sun Yat-Sen University,
Guangzhou 510120 , People's Republic of
China

Correspondence: Hai Huang Department of Urology, The Sun Yat-Sen Memorial Hospital, Sun Yat-Sen University, Guangzhou 510120, People's Republic of China

Email huanghai257@126.com
Background: Matrine (MAT) exhibits higher efficacy of chemotherapy when it is combined with other chemotherapeutic drugs; however, the therapeutic efficacy of matrine in combination with docetaxel (DOC) for prostate cancer, or even androgen-independent prostate cancer, remains poorly understood and the underlying molecular mechanisms have not yet been clearly defined. In the present study, we investigated whether matrine combined with docetaxel can strengthen anti-cancer effect.

Methods: In this study, 7 groups were established, including (1) blank control group (cells). (2) $0.1 \mathrm{~g} / \mathrm{L}$ MAT group, (3) $0.5 \mathrm{~g} / \mathrm{L}$ MAT group, (4) $0.1 \mathrm{~g} / \mathrm{L}$ MAT+ $50 \mu \mathrm{g} / \mathrm{L}$ DOC group, (5) $0.5 \mathrm{~g} / \mathrm{L}$ MAT $+50 \mu \mathrm{g} / \mathrm{L}$ DOC group, (6) $0.1 \mathrm{~g} / \mathrm{L}$ MAT+ $100 \mu \mathrm{g} / \mathrm{L}$ DOC group, and (7) $0.5 \mathrm{~g} / \mathrm{L}$ MAT $+100 \mu \mathrm{g} / \mathrm{L}$ DOC group. MTS assay was performed to detect the anti-proliferative effects of each group on DU145 and PC-3 cells. At the same time, Transwell assay was performed to detect anti-migrative and anti-invasive effects of each group on DU145 and PC3 cells. Biochemical colorimetric method and enzyme-linked immunosorbent assay were performed to detect the levels of LDH, IL-1 $\beta$ and IL-18 of each group on DU145 and PC-3 cells. Flow cytometry (FCM) assay was used to do the apoptosis analysis on DU145 and PC3 cells of each group. At last, Western blot analysis was performed to investigate the expression levels of caspase 1 in cells of each group. Statistical analyses were performed with SPSS 17.0 (SPSS Inc, USA) software, and one-way ANOVA and Fisher's exact test was taken.

Results: MTS assay showed that matrine combined with docetaxel could inhibit both DU145 and PC-3 cells' proliferation in a dose- and time-dependent manner. Transwell assay showed that matrine combined with docetaxel could inhibit both DU145 and PC-3 cells' migration and invasion in a dose- and time-dependent manner. The levels of LDH, IL-1 $\beta$ and IL-18 of matrine combined with docetaxel-treated DU145 and PC-3 cells were significantly increased, compared with the untreated control cells. Flow cytometry, as well as Annexin-V/PI staining, showed a significant and dose-dependent increase in the number of early, as well as late-stage apoptotic cells in both DU145 and PC-3 cells compared with the untreated control cells. Western blot analysis showed that matrine combined with docetaxel treatment led to the expression of caspase1 in both DU145 and PC-3 cells.

Conclusion: It may be more effective to use matrine in combination with docetaxel to treat androgen-resistant prostate cancer because matrine can help to affect proliferation, migration, invasion, apoptosis, metabolism, and have anti-inflammation effect on the tumor cells.

Keywords: matrine, docetaxel, androgen-independent prostate cancer, DU145, PC-3 


\section{Introduction}

Prostate cancer (PC) is the most prevalent male urogenital malignancy in the United States with 164,690 new cases predicted for 2018 and is the second leading cause of cancer death in US men with 29,430 deaths predicted for 2018. ${ }^{1,2}$ Although the incidence of prostate cancer is higher in Western countries and lower in Asian countries, increased life expectancy, changes in the environment, and improved diagnostic techniques have all contributed to the rise of prostate cancer in China in recent years. Prostate cancer has become the number one cancer of the urogenital system in China. ${ }^{3}$

The management of $\mathrm{PC}$ is still evolving. For the moment, early stages of the disease can be managed with active surveillance, radical prostatectomy, or radiation therapy, but no curative treatment exists for advanced disease (i.e. metastatic PC), which eventually develops in approximately $30 \%$ of patients with PC. ${ }^{4}$ The treatment for patients who are not suitable for surgical intervention is androgen deprivation (Castration). ${ }^{5}$ However, androgen deprivation treatment was reported to have long-term adverse effects, and was not curative for androgenindependent prostate cancer in $70-80 \%$ of the total number of patients, ${ }^{6,7}$ i.e. castration-resistant prostate cancer. Therefore, the developing of new treatments for androgenindependent prostate cancer has become the most important discussion in the global medicine world.

Matrine, an alkaloid extracted from the dry root of Sophora flavescens Aiton with low toxicity, has a molecular formula of $\mathrm{C} 15 \mathrm{H} 24 \mathrm{~N} 2 \mathrm{O} .{ }^{8}$ Our previous studies had shown that matrine can inhibit cell proliferation, migration, and invasion, and induce apoptosis in both DU145 and PC-3 cells. ${ }^{9,10}$ Although matrine combined with docetaxel has been used clinically to treat castration-resistant prostate cancer in recent years in China, however, the mechanismic research of matrine combined with docetaxel for the treatment of castration-resistant prostate cancer is less clear. In the present study, our aim was to explore the effects of matrine in combination with docetaxel on castration-resistant PC.

\section{Materials and Methods}

\section{Cell Culture}

Experiments in this study were performed with DU145 and PC3 cell lines, which were purchased from the Center for Experiment Animals of Sun Yat-sen University (Guangzhou, China). The use of the cell lines was approved by our institutional review board, and both cell lines were authenticated by STR profile. We purchased matrine and docetaxel from Sun Yat-sen University (Guangzhou, China). Cells were maintained in RPMI-1640 medium (Gibco, Grand Island, NY, USA) supplemented with $10 \%$ fetal bovine serum and 1\% penicillin-streptomycin solution (Invitrogen, Carlsbad, $\mathrm{CA}, \mathrm{USA}$ ) at $37^{\circ} \mathrm{C}$ and $5 \% \mathrm{CO}_{2}$.

\section{MTT Assay}

10,000 cells were seeded in 96-well plates (Corning, New York, NY, USA) containing $100 \mu \mathrm{L}$ culture medium plus matrine and docetaxel and they were incubated at $37^{\circ} \mathrm{C}$. After $24 \mathrm{hrs}$, we added $20 \mu \mathrm{L}$ MTT reagent to each well, incubated cells continuously at $37^{\circ} \mathrm{C}$ for $4 \mathrm{hrs}$, and absorbance was measured at $490 \mathrm{~nm}$ using a microplate reader (Multiskan MK3; Thermo Scientific, Shanghai, China).

\section{In vitro Invasion Assay}

The invasion assay were performed as previously described in a published study. ${ }^{10}$ We seeded cells $24 \mathrm{hrs}$ after treatment with matrine and docetaxel for $48 \mathrm{hrs}$. After seeding, the MEMF12 medium (c11330500bt; Invitrogen, Life Technologies) in the upper chambers was aspirated and replaced with serum-free medium and added $10 \%$ fetal bovine serum to the bottom chamber. Cells were incubated for $48 \mathrm{hrs}$ at $37^{\circ} \mathrm{C}$ and then fixed; the cells on the bottom of the filter were photographed and counted.

\section{Transwell Assay}

Cell lines were seeded into the upper chamber of a Transwell ${ }^{\circledR}$ well (BD, USA) for 24 hrs after treatment with matrine and docetaxel for $48 \mathrm{hrs}$. We filed the lower chamber of each well and incubated for $48 \mathrm{hrs}$ at $37^{\circ} \mathrm{C}$ and $5 \% \mathrm{CO}_{2}$. Cells were fixed and stained, then, non-migratory cells in the upper chamber were taken and migrated cells in 10 random high-power fields were counted.

\section{Detection of the Levels of IL-I $\beta$, IL-I8 and LDH}

Concentrations of IL-1 $\beta$, IL-18 and LDH in cell culture supernatants were measured after the DU145 and PC 3 cells were treated with matrine and docetaxel for $48 \mathrm{hrs}$ by using enzyme-linked immunosorbent assay (ELISA) kits (Biotech, USA) and biochemical colorimetric kits (Biyutian, Shanghai, China). The mean normalized OD450 values of IL- $1 \beta$ and IL-18 and OD560 values of LDH were obtained and concentrations were calculated with the values and the standard curve supplied by the manufacturer. 


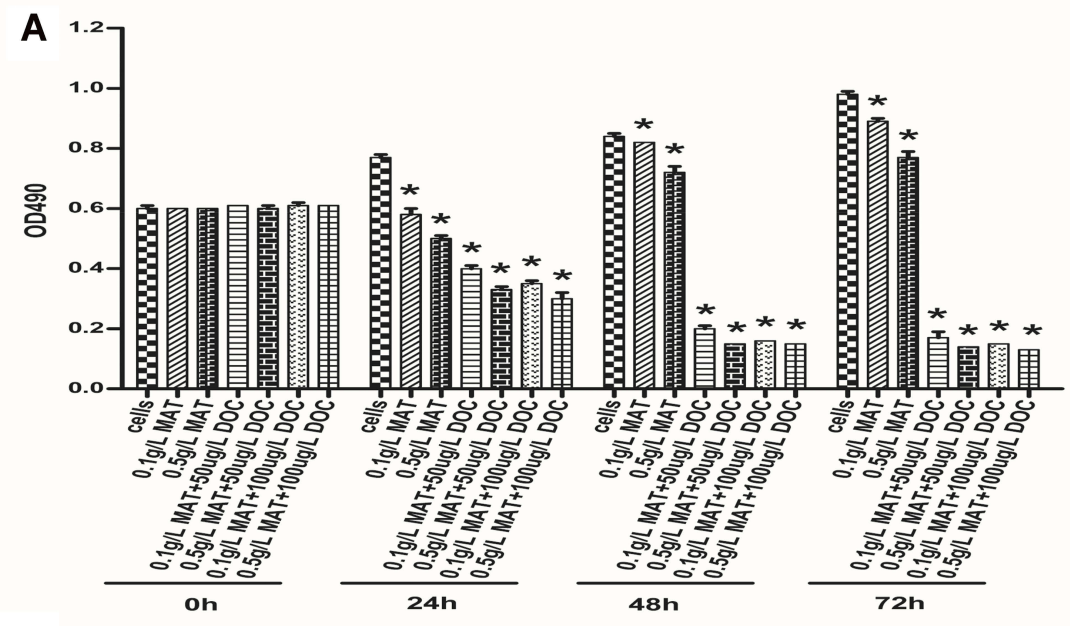

B
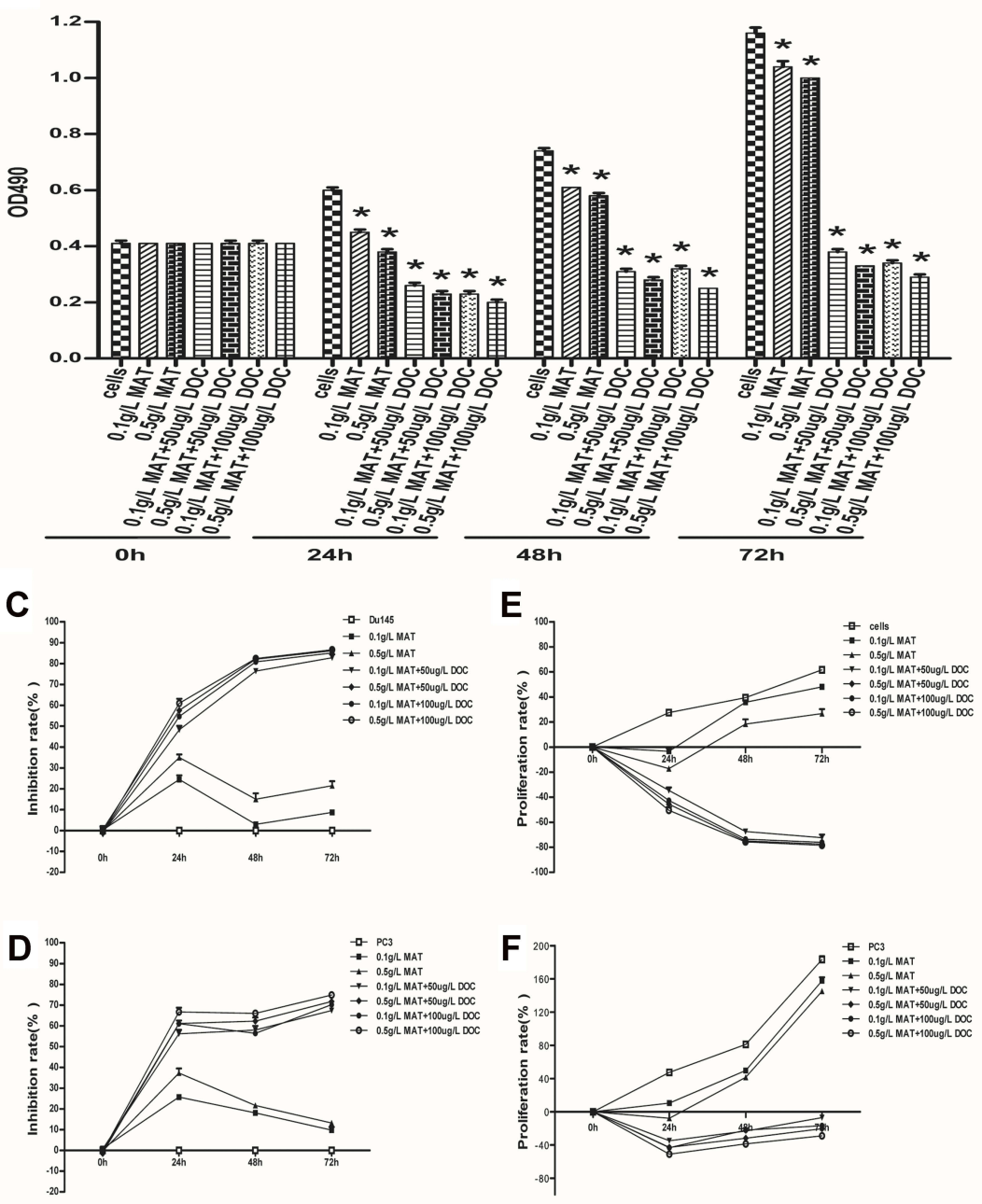

Figure I Matrine in combination with docetaxel reduces the proliferation of prostate cancer cells. (A, B) Plots of the cell growth of prostate DUI45 (A) and PC-3 cells (B) incubated with different concentrations of matrine and docetaxel for increasing time periods. Values of OD490 represent the number of viable cells. Data here or throughout are the average \pm standard deviation of at least three repeats. Statistical significance was determined by $t$-test. $* P \leq 0.05$. (C, $\mathbf{D})$ Plots of the growth inhibition rates of prostate DUI 45 (C) and PC-3 cells (D) incubated with different concentrations of matrine and docetaxel for increasing time periods. (E, F) Plots of the proliferation rates of prostate DUI45 (E) and PC-3 cells (F) incubated with different concentrations of matrine and docetaxel for increasing time periods. $* \mathrm{P} \leq 0.05$. 


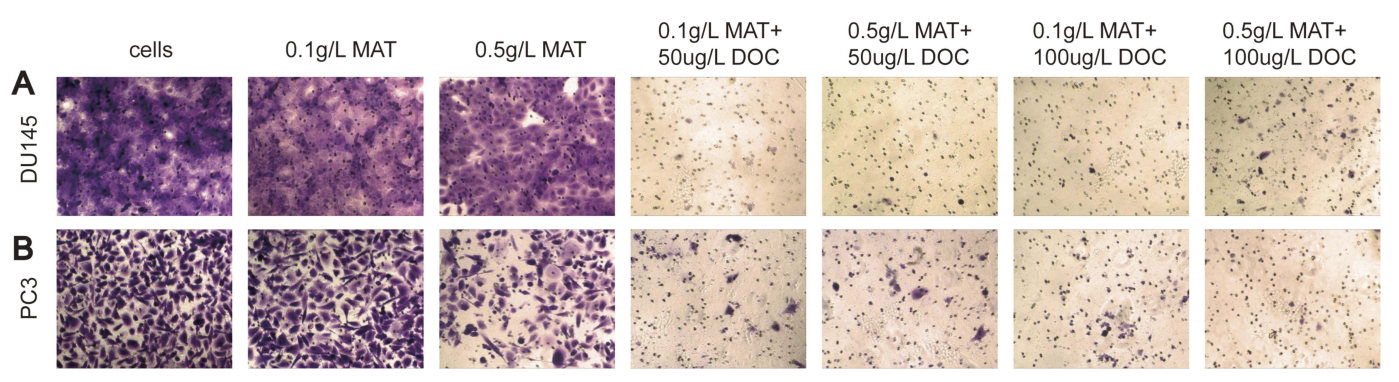

C

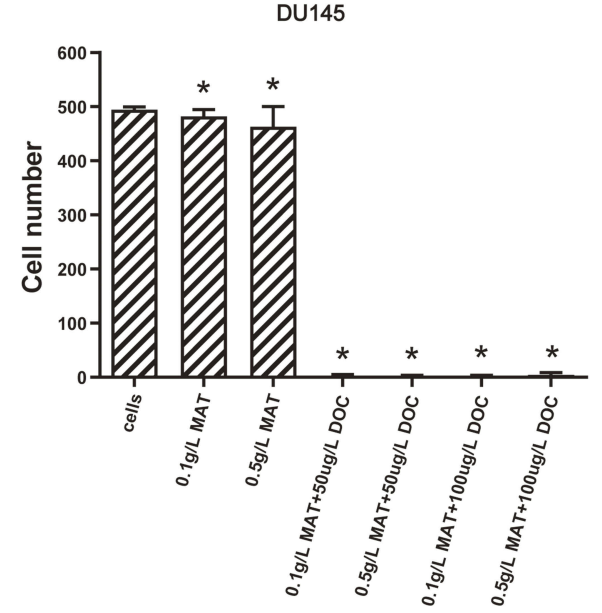

D
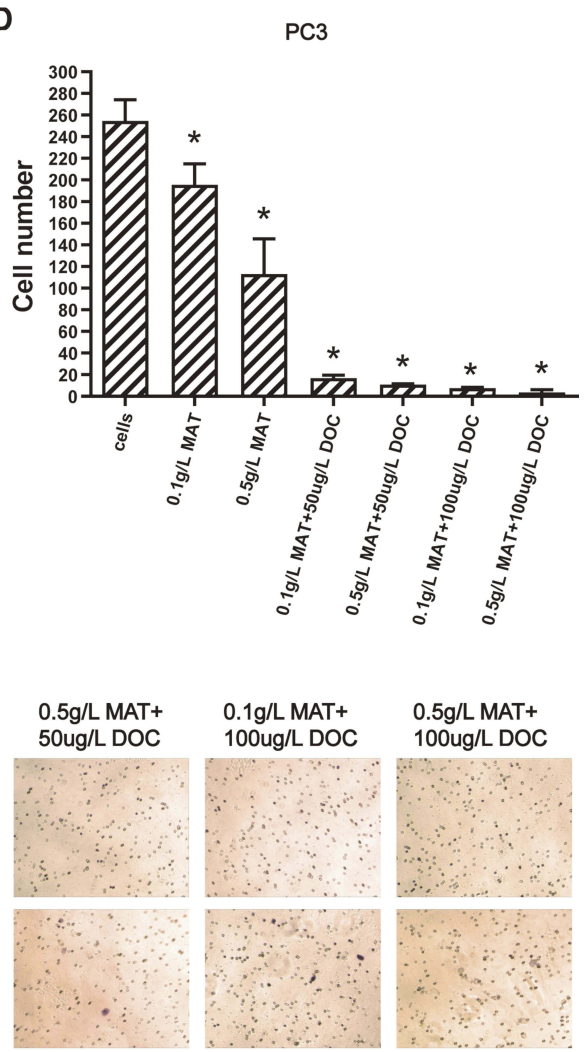

H

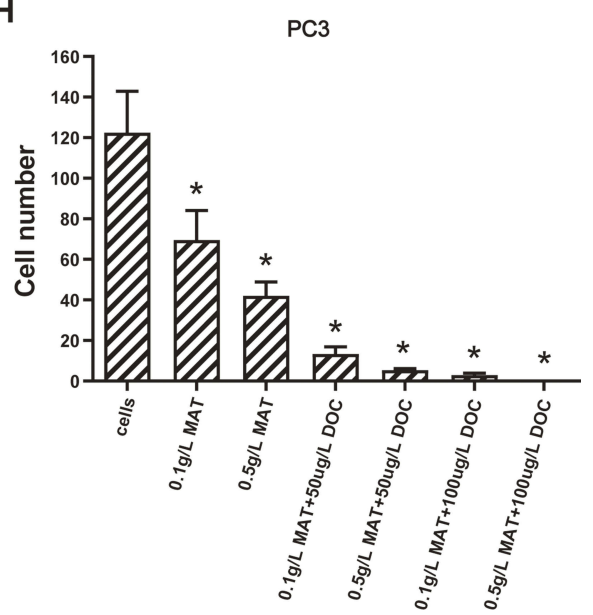

Figure 2 Matrine in combination with docetaxel impairs the invasion and migration of prostate cancer cells. (A-D) Representative images (A, B) and plots of the number (C, D) of invaded DUI45 (A, C) and PC-3 cells (B, D) per 10,000 seeded cells. (E-H) Representative images (E, F) and plots of the number (G, H) of migrated DUI45 (E, G) and PC-3 cells $(\mathbf{F}, \mathbf{H})$ per 10,000 seeded cells in the presence of different concentrations of matrine and docetaxel for $48 \mathrm{hrs}$. $* \mathrm{P} \leq 0.05$. 


\section{Analysis of Apoptotic Cells}

We evaluated apoptosis using the Annexin V/FITC apoptosis detection kit from BD. At first, we treated cells with different concentrations of matrine and docetaxel for $48 \mathrm{hrs}$ and harvested the cells by twice centrifugation at $1000 \mathrm{rpm}$ for 5 mins. Then we washed cells twice in binding buffer; $1 \times 10^{6}$ cells were re-suspended in $1 \mathrm{~mL}$ of binding buffer and incubated for 15 mins at room temperature in the dark. Cell cycles were analyzed by flow cytometry.

\section{Western Blot Analysis}

Western blot analysis was performed as previously described. ${ }^{10}$ The protein was boiled and subjected to Western blot with antibodies against caspase-1 $48 \mathrm{kDa}$, caspase-1 20 $\mathrm{kDa}$ and 1:1000 GAPDH (Kangcheng Biology, Shanghai, China). The blots were exposed, stained with ECL Plus (Millipore) and visualized on X-ray film. We calculated optical densities of the bands relative to the optical densities of the GAPDH bands from the same condition.

\section{Statistical Analysis}

Data were presented as mean \pm standard deviation (SD) and statistical significance was determined by ANOVA. Data concerning cell counts were analyzed by Fisher's exact test. Statistical analyses were performed with SPSS 17.0 software (SPSS Inc, USA). $\mathrm{P}<0.05$ was considered statistically significant.

\section{Results}

\section{Matrine in Combination with Docetaxel Suppresses the Growth of DUI45 and PC-3 Cells}

After treatment with matrine and docetaxel, both cell lines exhibited a dose- and time-dependent growth inhibition (Figure 1A and B). The growth inhibition rates of DU145 and PC-3 cells reached as high as $86 \%$ and $74 \%$, respectively, when cells were treated with $0.5 \mathrm{~g} / \mathrm{L}$ matrine and $100 \mu \mathrm{g} / \mathrm{L}$ docetaxel for $72 \mathrm{hrs}$ (Figure 1C and D). Therefore, matrine in combination with docetaxel effectively suppressed the growth of both androgen-independent prostate cancer cell lines DU145 and PC-3.

\section{Matrine in Combination with Docetaxel Inhibits the Invasion and Migration of Both DUI45 and PC-3 Cells}

After treatment with matrine and docetaxel for $48 \mathrm{hrs}$, both cell lines exhibited significantly reduced abilities of invasion and
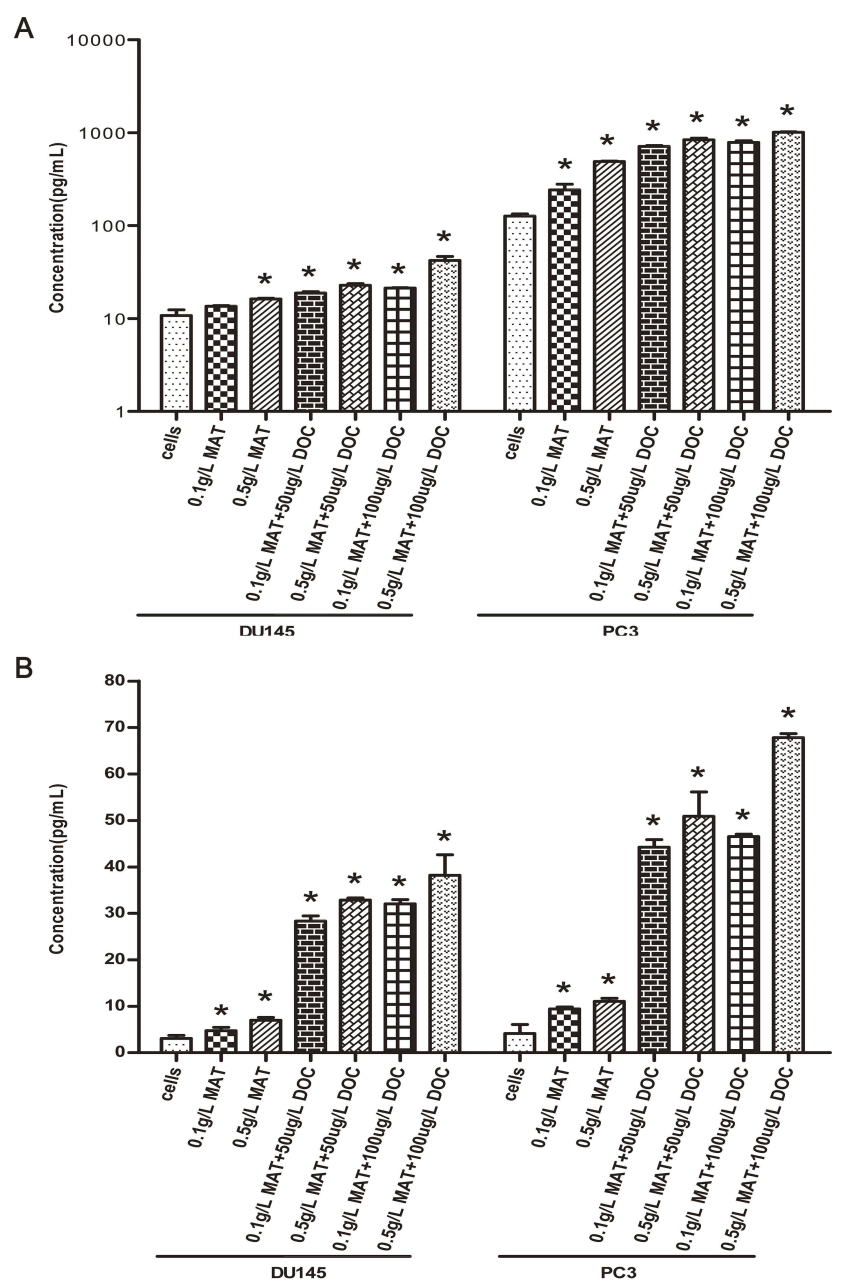

C

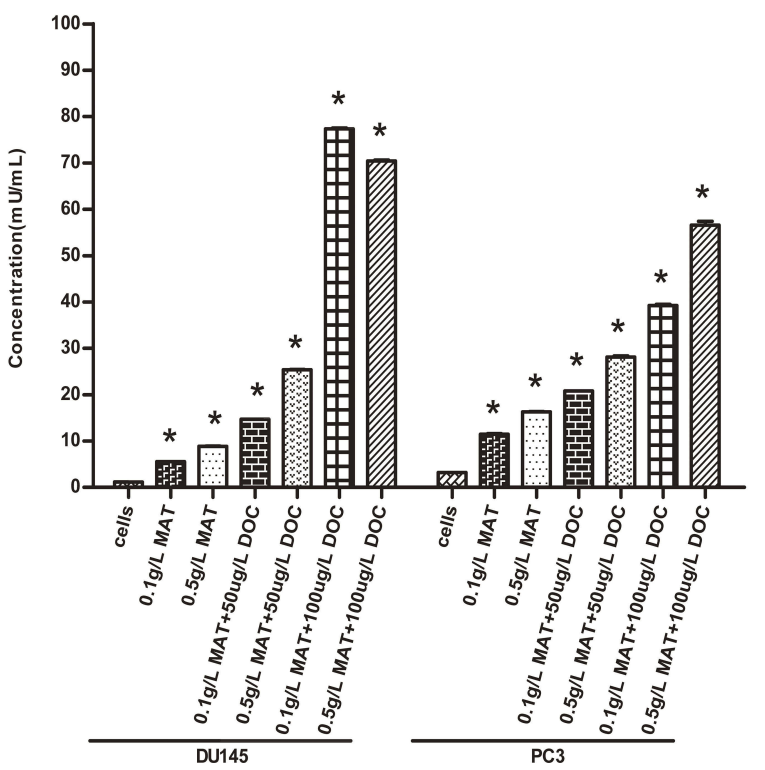

Figure 3 Matrine in combination with docetaxel promote the levels of IL-I $\boldsymbol{\beta}(\mathbf{A})$, IL-I8 (B), and LDH (C) in prostate cancer cells. ${ }^{*} \mathrm{P} \leq 0.05$.

migration in a dose-dependent manner $(P<0.05$, ANOVA analysis) (Figure 2). The inhibitory effects of matrine combined 
with docetaxel on the invasion of DU145 and PC-3 cells were near $100 \%$ when the DU145 cells were treated with $0.5 \mathrm{~g} / \mathrm{L}$ matrine combined with $50 \mu \mathrm{g} / \mathrm{L}$ docetaxel and the PC-3 cells were treated with $0.5 \mathrm{~g} / \mathrm{L}$ matrine combined with $100 \mu \mathrm{g} / \mathrm{L}$ docetaxel, respectively, for $48 \mathrm{hrs}$ (Figure 2A-D). The inhibitory impacts of matrine on the migration of both DU145 and PC-3 cells were also close to $100 \%$ when the cells were treated with $0.5 \mathrm{~g} / \mathrm{L}$ matrine combined with $100 \mu \mathrm{g} / \mathrm{L}$ docetaxel for 48 hrs (Figure 2E-H). Thus, matrine, in combination with docetaxel, effectively impaired the migration and invasion of both DU145 and PC-3 cells.

\section{Matrine in Combination with Docetaxel Promote the Levels of IL-I $\beta$, IL-I8, and LDH in Prostate Cancer Cells}

To determine the anti-inflammation function of matrine and docetaxel, both cell lines were treated with matrine and docetaxel for $48 \mathrm{hrs}$. The levels of IL-1 $\beta$, IL-18, and LDH were significantly increased upon exposure to matrine combined with docetaxel (Figure 3). The results suggest that matrine, in combination with docetaxel, enhances the anti-inflammation function of androgen-independent prostate cancer cells.
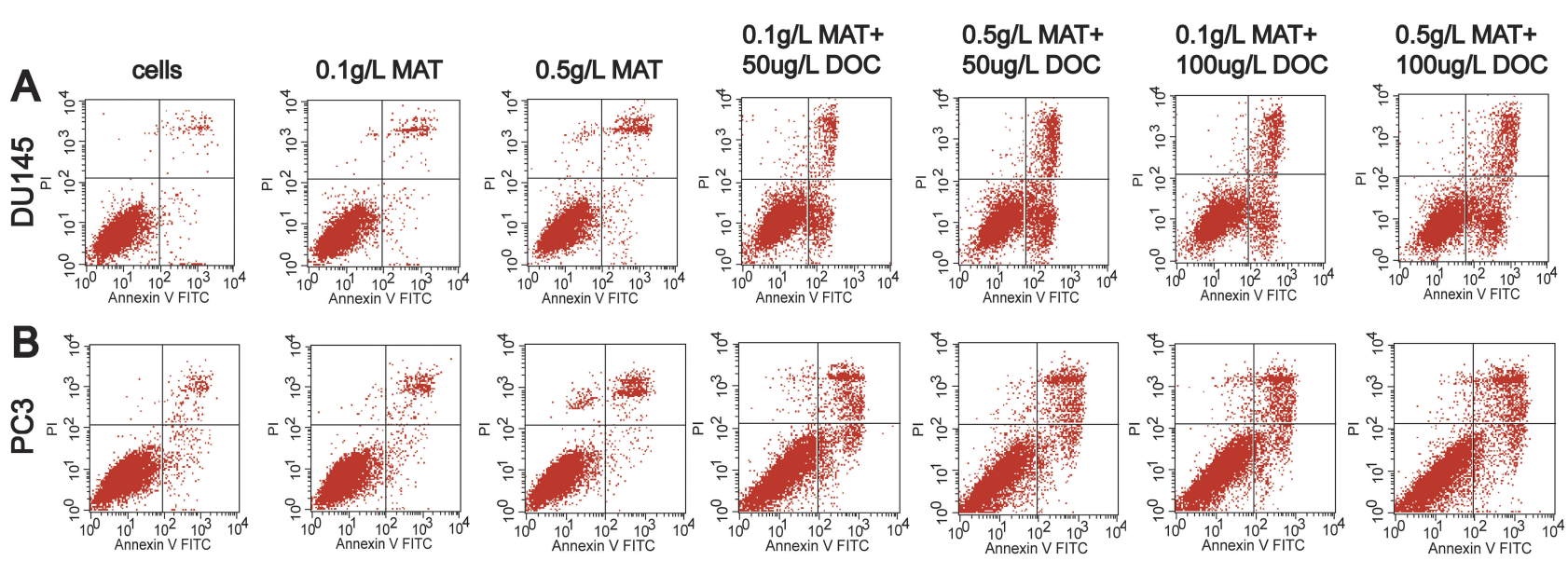
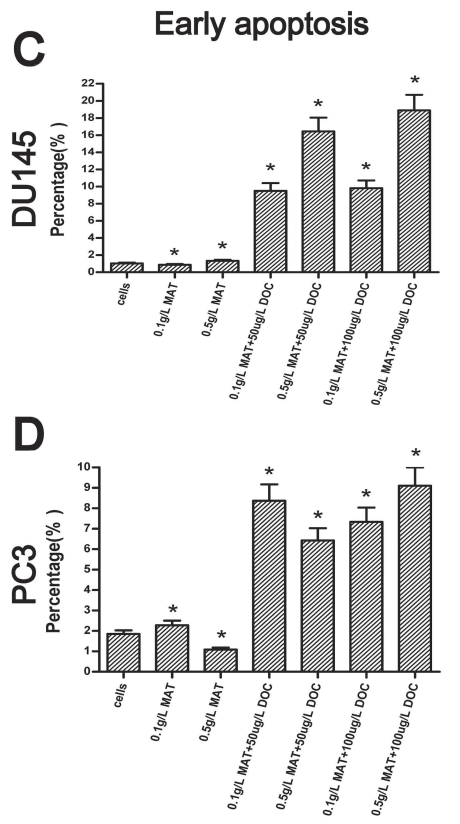

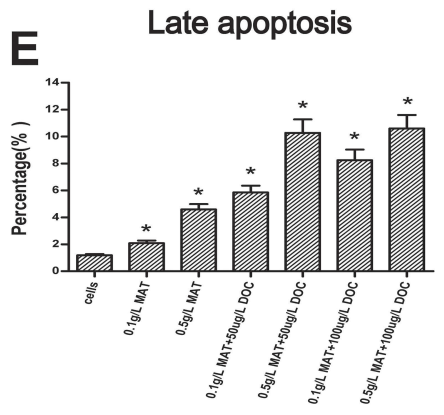

F

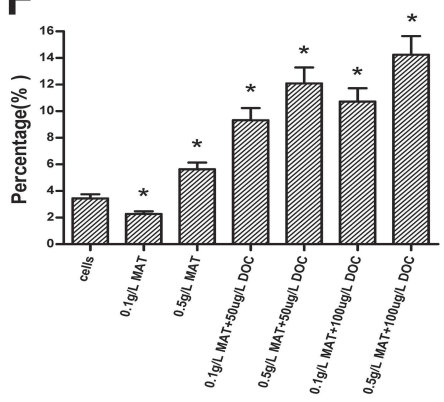

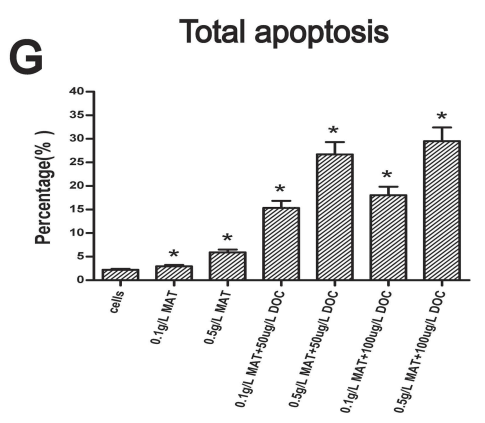

H

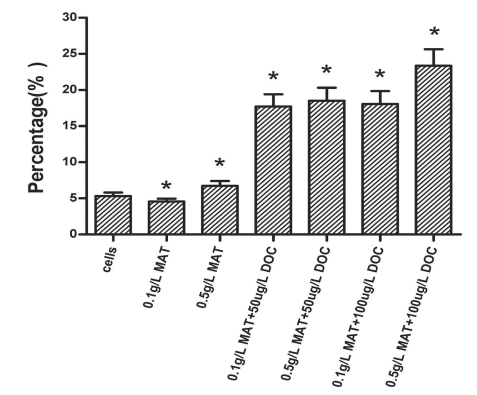

Figure 4 Matrine in combination with docetaxel promotes the apoptosis of prostate cancer cells. (A, B) Representative dot plots of apoptotic cells detected in the DUI45 (A) and PC-3 cells (B) treated with different concentrations of matrine and docetaxel by flow cytometry. (C-H) Plots of the percentages of early (C, D), late (E, F), and total apoptotic cells $(\mathbf{G}, \mathbf{H})$ in the DUI45 (C, E, G) and PC-3 cells $(\mathbf{D}, \mathbf{F}, \mathbf{H})$ treated with different concentrations of matrine and docetaxel. *P $\leq 0.05$. 


\section{Matrine in Combination with Docetaxel Increases the Apoptotic Cell Population}

We analyzed the impact of matrine in combination with docetaxel on cell apoptosis by flow cytometry. Both cell lines exhibited significant increases in the apoptotic cell population upon exposure to matrine combined with docetaxel (Figure 4). Therefore, matrine, in combination with docetaxel, suppresses DNA replication and enhances apoptosis.

\section{Matrine in Combination with Docetaxel Promote the Expression Levels of Caspase-I 48 kDa and Caspase-I 20 kDa in Prostate Cancer Cells}

To determine the impact of matrine and docetaxel on the expression levels of protein involved in the cellular apoptosis, DU145 and PC-3 cells were treated with the two drugs for $48 \mathrm{hrs}$. The levels of caspase-1 $48 \mathrm{kDa}$ and caspase-1 $20 \mathrm{kDa}$ in cell lines were significantly increased upon exposure to matrine combined with docetaxel (Figure 5). The results show that matrine, in combination with docetaxel, enhances the apoptosis of androgenindependent prostate cancer cells.

\section{Discussion}

Currently, in China, a lot of hospitals, including hospitals of integral medicine of traditional Chinese and western medicine, use combined methods of the traditional Chinese medicine and western medicine to treat a number of types of cancer and it was demonstrated that this kind of combined treatment was of efficiency and safety in clinic. However, the exact therapeutic efficacy and the exact mechanisms remain poorly understood.

In our previous study, it has been proved that matrine could inhibit the proliferation of PC-3 and DU145 cells dose-dependently and time-dependently. ${ }^{8,10}$ In the present study, we evaluated the antitumor effect of matrine in combination with docetaxel on androgen-independent prostate cancer cells DU145 and PC-3. We showed that

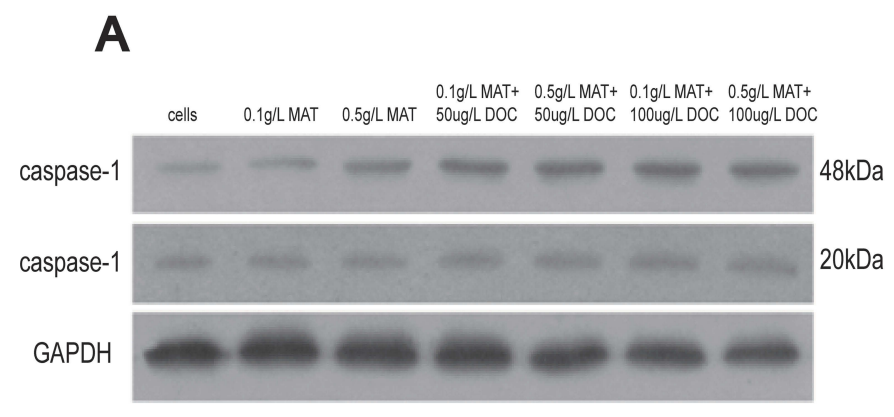

C

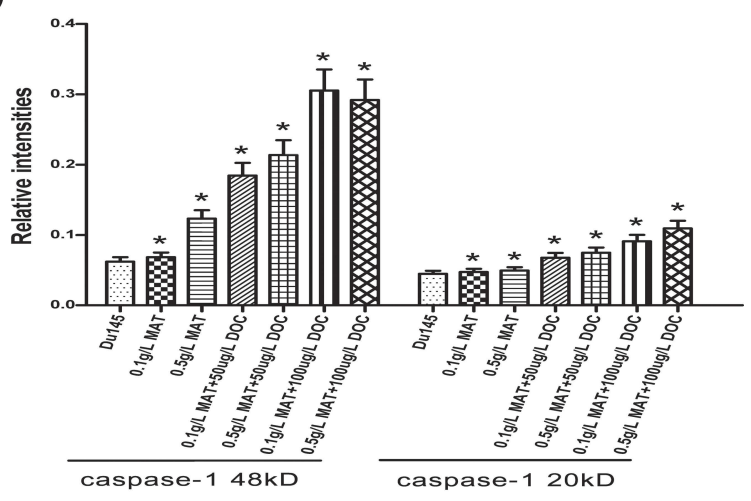

B

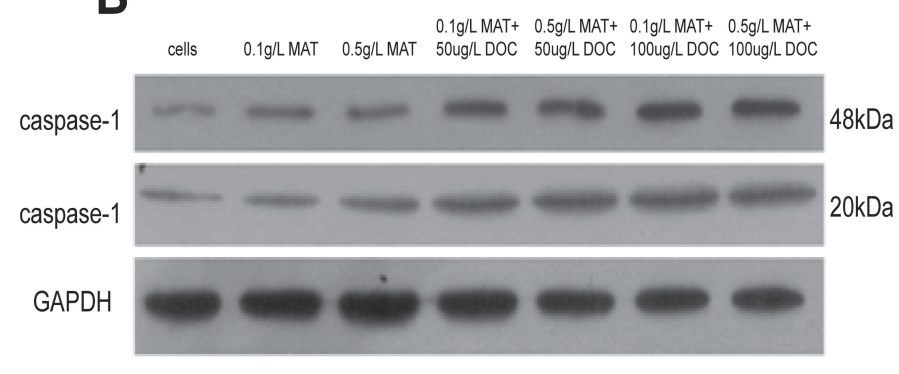

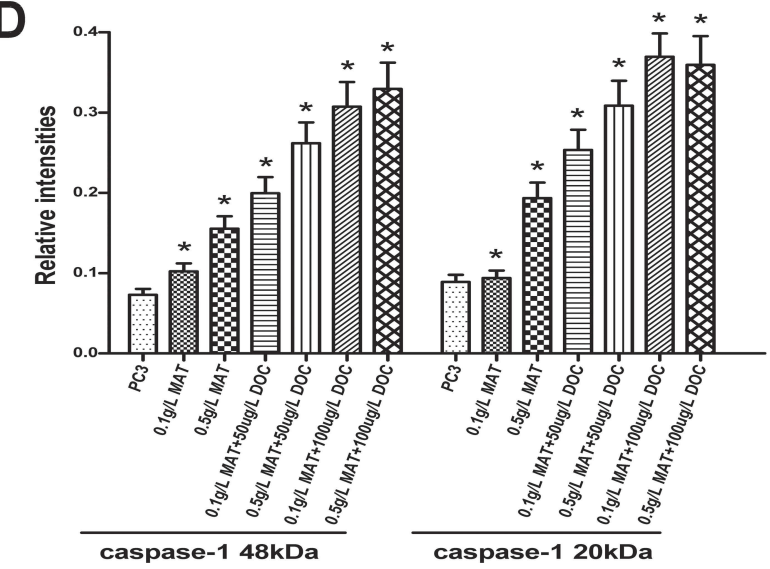

Figure 5 Matrine in combination with docetaxel promote the expression levels of caspase- $48 \mathrm{kDa}$ and caspase-I $20 \mathrm{kDa}$ in prostate cancer cells. (A, B) Representative immunoblot results showing the intensities of caspase-I $48 \mathrm{kDa}$ and caspase-I $20 \mathrm{kDa}$ in DUI45 (A) and PC-3 cells (B) treated with matrine and docetaxel at the concentrations as indicated. (C, D) Plots of the relative intensities of proteins shown in panels $A$ and $B$ as representatives against different concentrations of matrine and docetaxel in DUI45 (C) and PC-3 cells (D). Levels of proteins are the ratios to GAPDH levels. *P $\leq 0.05$. 
matrine combined with docetaxel is effective to inhibit the proliferation, migration, and invasion of both DU145 and PC3 cells to some extent.

The level of LDH, an indicator of tumor metabolism and tumor burden, is very important to prostate cancer. ${ }^{11-13}$ In the present study, we evaluated that matrine combined with docetaxel can inhibit tumor cells by changing the tumor cell metabolism and survival environment.

Inflammation is an important hallmark of all cancers and quite a bit of epidemiological studies indicate that prostate inflammation is associated with increased risk of prostate cancer. $^{14,15}$ And the levels of IL-18 and IL-1 $\beta$ is associated with cellular inflammation thought to be linked to prostate carcinogenesis and prostate cancer development. ${ }^{15-21}$ In consequence, matrine combined with docetaxel also maybe inhibit tumor cells by promoting the levels of IL-18 and IL$1 \beta$ and suppressing inflammation.

Therefore, it may be more effective to use matrine in combination with docetaxel to treat androgen-resistant prostate cancer because it can affect the tumor cell proliferation, migration, invasion, apoptosis, metabolism, and thus shows anti-inflammatory effects.

\section{Acknowledgments}

This work was supported by the National Natural Science Foundation of China Grant \#: 81472382; the National Natural Science Foundation of China for Young Scientists Grant \#: 81101947; the Guangdong Province Natural Science Foundation \#: 2014A030313079; the Fundamental Research Funds for the Central Universities \#: 14ykpy19; Guangdong Province Science and Technology for Social Development Project Grant \#: 2013B021800107; Guangzhou City in 2015 scientific research projects \#: 7415600066401 to Hai Huang.NIH NCI 1R01CA142862 to Leyuan Liu.

\section{Disclosure}

The authors declare that there is no conflict of interest.

\section{References}

1. Streicher J, Meyerson BL. A review of optimal prostate biopsy: indications and techniques.Ther Advan Urol. 2019;11:175628721 9870074.

2. American Cancer Society. Cancer Facts \& Figures 2018. Atlanta, GA: American Cancer Society; 2018.

3. Sim HG, Cheng CWS. Changing demography of prostate cancer in Asia. Eur J Cancer. 2005;41(6):834-845. doi:10.1016/j.ejca.2004.12.033
4. Climent MA, Leon-Mateos L, Gonzalez Del Alba A, et al. Updated recommendations from the Spanish Oncology Genitourinary Group for the treatment of patients with metastatic castration-resistant prostate cancer. Crit Rev Oncol Hematol. 2015;96(2):308-318.

5. Quon H, Loblaw DA. Androgen deprivation therapy for prostate cancer - review of indications in 2010. Curr Oncol. 2010;17(Suppl 2):S38-44. doi:10.3747/co.v17i0.698

6. Gioeli D. Signal transduction in prostate cancer progression. Clin Sci. 2005;108(4):293-308. doi:10.1042/CS20040329

7. Golabek T, Belsey J, Drewa T, et al. Evidence-based recommendations on androgen deprivation therapy for localized and advanced prostate cancer. Cent European J Urol. 2016;69(2):131-138. doi:10.5173/ceju.2016.812

8. Li Q, Huang H, He Z, et al. Regulatory effects of antitumor agent matrine on FOXO and PI3K-AKT pathway in castration-resistant prostate cancer cells. Sci China Life Sci. 2018;61(5):550-558. doi:10.1007/s11427-016-9050-6

9. Huang H, Wang Q, Du T, et al. Matrine inhibits the progression of prostate cancer by promoting expression of GADD45B. Prostate. 2018;78(5):327-335.

10. Li Q, Lai Y, Wang C, et al. Matrine inhibits the proliferation, invasion and migration of castration-resistant prostate cancer cells through regulation of the NF-kappaB signaling pathway. Oncol Rep. 2016;35(1):375-381.

11. Vaz CV, Marques R, Alves MG, et al. Androgens enhance the glycolytic metabolism and lactate export in prostate cancer cells by modulating the expression of GLUT1, GLUT3, PFK, LDH and MCT4 genes. J Cancer Res Clin Oncol. 2016;142(1):5-16. doi:10.1007/s00432-015-1992-4

12. Scher HI, Heller G, Molina A, et al. Circulating tumor cell biomarker panel as an individual-level surrogate for survival in metastatic castration-resistant prostate cancer. J Clin Oncol. 2015;33 (12):1348-1355. doi:10.1200/JCO.2014.55.3487

13. Keshari KR, Sriram R, Van Criekinge M, et al. Metabolic reprogramming and validation of hyperpolarized $13 \mathrm{C}$ lactate as a prostate cancer biomarker using a human prostate tissue slice culture bioreactor. Prostate. 2013;73(11):1171-1181. doi:10.1002/pros.v73.11

14. De Marzo AM, Platz EA, Sutcliffe S, et al. Inflammation in prostate carcinogenesis. Nat Rev Cancer. 2007;7(4):256-269. doi:10.1038/ nrc2090

15. Thapa D, Ghosh R. Chronic inflammatory mediators enhance prostate cancer development and progression. Biochem Pharmacol. 2015;94 (2):53-62. doi:10.1016/j.bcp.2014.12.023

16. Staverosky JA, Zhu XH, Ha S, Logan SK. Anti-androgen resistance in prostate cancer cells chronically induced by interleukin-1beta. $\mathrm{Am}$ J Clin Exp Urol. 2013;1(1):53-65.

17. Yencilek F, Yildirim A, Yilmaz SG, et al. Investigation of interleukin-1beta polymorphisms in prostate cancer. Anticancer Res. 2015;35(11):6057-6061.

18. Xu H, Hu MB, Bai PD, et al. Proinflammatory cytokines in prostate cancer development and progression promoted by high-fat diet. Biomed Res Int. 2015;2015:249741.

19. Liu JM, Liu JN, Wei MT, et al. Effect of IL-18 gene promoter polymorphisms on prostate cancer occurrence and prognosis in Han Chinese population. Genet Mol Res. 2013;12(1):820-829. doi:10.4238/2013. March.15.2

20. Dwivedi S, Goel A, Natu SM, Mandhani A, Khattri S, Pant KK. Diagnostic and prognostic significance of prostate specific antigen and serum interleukin 18 and 10 in patients with locally advanced prostate cancer: a prospective study. Asian Pac J Cancer Prev. 2011;12 (7): $1843-1848$.

21. Tse BW, Russell PJ, Lochner M, Forster I, Power CA. IL-18 inhibits growth of murine orthotopic prostate carcinomas via both adaptive and innate immune mechanisms. PLOS ONE. 2011;6(9):e24241. doi:10.1371/ journal.pone. 0024241 


\section{Publish your work in this journal}

Cancer Management and Research is an international, peer-reviewed open access journal focusing on cancer research and the optimal use of preventative and integrated treatment interventions to achieve improved outcomes, enhanced survival and quality of life for the cancer patient.
The manuscript management system is completely online and includes a very quick and fair peer-review system, which is all easy to use. Visit http://www.dovepress.com/testimonials.php to read real quotes from published authors.

Submit your manuscript here: https://www.dovepress.com/cancer-management-and-research-journal 